Article

\title{
Decoration of Ag Nanoparticle on ZnO Nanowire by Intense Pulsed Light and Enhanced UV Photodetector
}

\author{
Youngwook Noh ${ }^{1}$, Jaehak Shin ${ }^{1}$, Horim Lee ${ }^{1}$, Gyu Young Kim ${ }^{1}$, Manoj Kumar ${ }^{2}$ and Dongjin Lee ${ }^{1, *(D)}$ \\ 1 Department of Mechanical Design and Production Engineering, Konkuk University, Seoul 05029, Korea; \\ kiwonno2@konkuk.ac.kr (Y.N.); dftd93@konkuk.ac.kr (J.S.); lhr2234@konkuk.ac.kr (H.L.); \\ glen@konkuk.ac.kr (G.Y.K.) \\ 2 Department of Physics, Starex University, Gurugram 122413, India; manojkumar@starexuniversity.com \\ * Correspondence: djlee@konkuk.ac.kr
}

check for updates

Citation: Noh, Y.; Shin, J.; Lee, H.; Kim, G.Y.; Kumar, M.; Lee, D.

Decoration of Ag Nanoparticle on ZnO Nanowire by Intense Pulsed Light and Enhanced UV Photodetector. Chemosensors 2021, 9, 321. https://doi.org/10.3390/ chemosensors 9110321

Academic Editors: Simas Rackauskas and Agne Sulciute

Received: 21 October 2021

Accepted: 12 November 2021

Published: 15 November 2021

Publisher's Note: MDPI stays neutral with regard to jurisdictional claims in published maps and institutional affiliations.

Copyright: (c) 2021 by the authors. Licensee MDPI, Basel, Switzerland. This article is an open access article distributed under the terms and conditions of the Creative Commons Attribution (CC BY) license (https:// creativecommons.org/licenses/by/ $4.0 /)$.

\begin{abstract}
Zinc oxide (ZnO) nanowires (NWs) are wide-bandgap semiconductors that absorb ultraviolet (UV) radiation. Various post-treatment processes have been studied to improve the optical properties of the as-grown ZnO NWs. Among them, Ag nanoparticles (NPs) effectively improved the optical properties on the surface of the ZnO NWs. In this study, ZnO NWs were synthesized via the hydrothermal synthesis method. ZnO NWs were decorated with Ag NPs on the surface of the $\mathrm{ZnO} N W s$ in a silver nitrate $\left(\mathrm{AgNO}_{3}\right)$ aqueous solution by intense pulsed light (IPL) irradiation. $\mathrm{Ag}$ NPs were successfully decorated under the following conditions: aqueous $\mathrm{AgNO}_{3}$ solution of $100 \mathrm{nM}$, an energy of $1 \mathrm{~J} / \mathrm{cm}^{2}$, and an exposure time of $8 \mathrm{~ms}$. The responsivity and sensitivity of the ZnO NW UV photodetectors increased by 7.43 and 3.37 times, respectively. The IPL process makes it possible to decorate Ag NPs in a simple manner within an extremely short time.
\end{abstract}

Keywords: intense pulsed light (IPL); ZnO nanowire; Ag nanoparticles; nanocomposites; UV photodetector

\section{Introduction}

Zinc oxide $(\mathrm{ZnO})$ is a wide-bandgap semiconductor with a bandgap of $3.37 \mathrm{eV}$ and absorbs ultraviolet (UV) radiation, thus causing an electron transition from the valence to the conduction band [1-3]. It also has a high-exciton binding energy of $\sim 60 \mathrm{meV}$ and exhibits biological inertness at room temperature [4-6]. Particularly, ZnO nanostructures can be easily synthesized by a low-temperature (below $100{ }^{\circ} \mathrm{C}$ ) solution process [7-9]. They are attracting great attention in research and industrial sectors, because they can be implemented in various forms of thin-films (TFs) [10], nanoparticles (NPs) [11], nanowires (NWs) [8], nanorods (NRs) [12], nanosheets (NSs) [13], nanobelts [14], nanotubes [15], and nanoflowers [16]. ZnO exhibits excellent performance in electronics, optics, and photonics, and finds a variety of applications, such as in light-emitting diodes [17], photocatalysts [18], gas sensors [19], biosensors [20], nanogenerators [21], and UV photodetectors (PDs) [7]. In particular, $\mathrm{ZnO}$ has attracted significant attention as an optoelectronic device. $\mathrm{ZnO}$ has thermal and chemical stability, environmental friendliness, and ultra-high radiation hardness, making it suitable for photonic applications on the UV spectral range without additional filters [22,23].

Attempts have been made to improve the properties of $\mathrm{ZnO}$ with annealing [24], impurity doping [25], plasma treatment [26], and UV treatment [27]. In addition, Ag NPs were incorporated to improve the properties using thermal techniques [28], UV techniques [29], evaporation [30], sputtering [31], and electrodeposition [32]. Among them, the thermal and UV techniques have employed the solution process. The advantage of a solution process is its inexpensiveness compared with the vacuum process. However, it is a time-consuming process. The reported process times for thermal and UV techniques were $3 \mathrm{~h}$ and $30 \mathrm{~min}$, respectively [28,33]. Furthermore, the thermal technique requires 
exposure to high temperatures amounting to several hundred degrees [28]. Conversely, the intense pulsed light (IPL) process is facile, rapid, and efficient at room temperature. Therefore, replacing the energy source from heat or UV to IPL can be advantageous.

In this study, we decorated Ag NPs using a facile and rapid IPL process to improve the properties of the hydrothermally as-grown $\mathrm{ZnO} N W$ s and fabricated the Ag-decorated $\mathrm{ZnO}$ NW UV PDs. The ZnO NWs were synthesized via a typical hydrothermal synthesis method. Hydrothermal synthesis is the most well-known method for synthesizing vertically aligned $\mathrm{ZnO}$ NWs directly on the substrate in a solution process [34]. Compared with the other methods, the hydrothermal method is a potential and effective way to synthesize $\mathrm{ZnO}$ nanowires with the advantages of mild reaction conditions, environment-friendly, and easy to control [35]. Furthermore, it is easy to manufacture single-crystalline nanostructures [36]. The Ag decoration was carried out in an $\mathrm{AgNO}_{3}$ aqueous solution by varying the concentration and irradiation energy of IPL. The IPL irradiation was performed for an extremely short time on the order of milliseconds. The Ag-decorated $\mathrm{ZnO}$ NWs were characterized by several analytical techniques. Finally, the Ag-decorated $\mathrm{ZnO}$ NWs were exploited in UV PDs to demonstrate enhanced properties, thereby improving the performance of UV PDs.

\section{Materials and Methods}

\subsection{Synthesis of $\mathrm{ZnO} N \mathrm{NS}$}

Figure 1 shows the fabrication process of the Ag-decorated ZnO NW UV PDs, including hydrothermal growth of $\mathrm{ZnO}$ NWs, Ag-decoration with IPL, and formation of electrodes using ink-jet printing. First, the $\mathrm{ZnO}$ NWs were synthesized using the hydrothermal method $[8,37]$. The $\mathrm{Zn}$ seed layer was prepared on a $\mathrm{SiO}_{2} / \mathrm{Si}$ substrate by sol-gel spin-coating of a mixture of zinc acetate dihydrate $(0.5 \mathrm{M})$ and diethanolamine $(0.5 \mathrm{M})$ in ethanol at $4000 \mathrm{rpm}$ for $30 \mathrm{~s}$. It was followed by heat-treatment at $350{ }^{\circ} \mathrm{C}$ for $30 \mathrm{~min}$ on a hotplate. Subsequently, $\mathrm{ZnO}$ NWs were grown hydrothermally at $90^{\circ} \mathrm{C}$ for $4 \mathrm{~h}$ in a mixture of zinc nitrate hexahydrate $(25 \mathrm{mM})$ and hexamethylenetetramine $(25 \mathrm{mM})$ in deionized (DI) water.

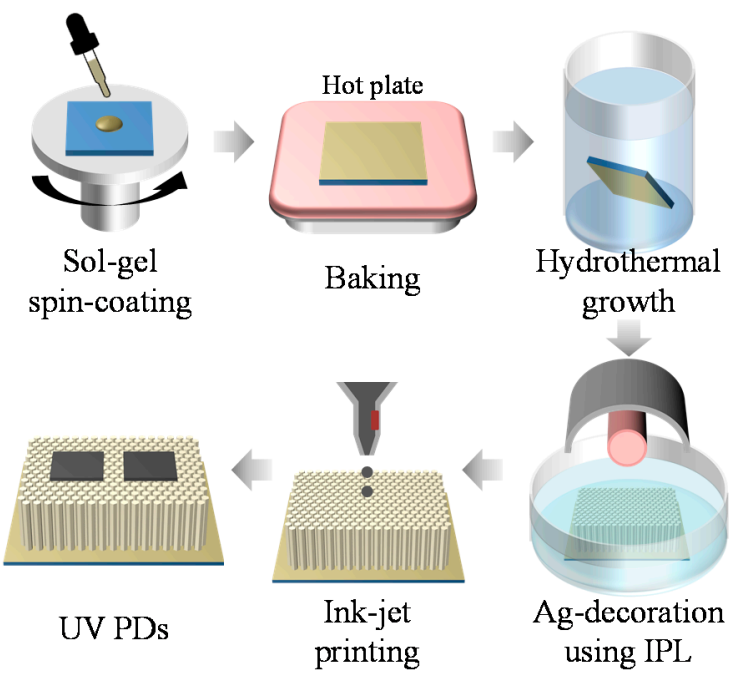

Figure 1. Schematic of fabrication for the Ag-decorated ZnO NW UV PDs.

\subsection{Ag Decoration on as-Grown $\mathrm{ZnO} N W s$}

The as-grown $\mathrm{ZnO}$ NWs were decorated with Ag NPs using a facile and rapid IPL process. The $\mathrm{SiO}_{2} / \mathrm{Si}$ substrate on which $\mathrm{ZnO}$ NWs have been grown was dipped into silver nitrate $\left(\mathrm{AgNO}_{3}\right)$ in DI water followed by IPL exposure. $\mathrm{AgNO}_{3}$ played the role of precursor for Ag NPs. The IPL equipment used in this study was composed of a Xenon flash lamp (P4128, Heraeus Co., Hanau, Germany), pulse controller (PSTEK Co., Gunpo, Korea), power supply, capacitors, and chilling unit. The concentrations of the $\mathrm{Ag}$ precursor and IPL irradiation energy were adopted as process variables in the Ag-decoration process. 
The IPL exposure was conducted with a single exposure, which lasted $8 \mathrm{~ms}$. After the IPL process, the substrate was thoroughly rinsed with DI water.

\subsection{Fabrication of $U V P D s$}

The electrodes were fabricated on the Ag-decorated $\mathrm{ZnO}$ NWs by printing silver ink (DGP 40LT-13C, Advanced Nano Products Co., Sejong, Korea) with an ink-jet printer (DMP-2831, FUJIFILM Dimatix Co., Santa Clara, CA, USA) for UV PDs. The electrodes had dimensions of $2 \mathrm{~mm} \times 2 \mathrm{~mm}$ and a channel length of $120 \mu \mathrm{m}$.

\subsection{Characterization}

Field-emission scanning electron microscopy (FE-SEM) (S-4800, Hitachi Co., Tokyo, Japan), high-resolution transmission electron microscopy (HR-TEM) (JEM-2100F, JEOL Co., Tokyo, Japan), and energy-dispersive X-ray spectroscopy (EDS) were used for morphological study of Ag-decorated ZnO NWs. X-ray photoelectron spectroscopy (XPS) (K-Alpha, Thermo Fisher Scientific Co., Waltham, MA, USA) and photoluminescence (PL) spectroscopy (LS55, PerkinElmer Co., Waltham, MA, USA) were used to analyze photocurrent characteristics. The performance of UV PDs was measured with a source meter (2634B, Keithley Instruments Co., Cleveland, OH, USA) using a UV light-emitting diode (LED) at a wavelength of $365 \mathrm{~nm}$.

\section{Results and Discussion}

\subsection{Ag-Decorated $\mathrm{ZnO}$ NWs}

The SEM images of the hydrothermally as-grown $\mathrm{ZnO}$ NWs are shown in Figure 2. The $\mathrm{ZnO}$ NWs were grown vertically on the $\mathrm{SiO}_{2} / \mathrm{Si}$ substrate and are densely packed. They have an average diameter and length of $42 \mathrm{~nm}$ and $840 \mathrm{~nm}$, respectively. The grown $\mathrm{ZnO}$ NWs exhibit the hexagonal wurtzite structure, as shown in Figure 2a. This observation is quite consistent with previous studies [8,9]. However, it was difficult to identify the decorated Ag NPs with SEM, which have been done with TEM. Figure 2c,d show ZnO NWs processed for 5 and $15 \mathrm{~s}$ in $\mathrm{AgNO}_{3}$ concentration of $1 \mathrm{mM}$ at an IPL energy of $1 \mathrm{~J} / \mathrm{cm}^{2}$ per pulse and frequency of $6 \mathrm{~Hz}$, respectively. $\mathrm{ZnO} \mathrm{NWs}$ are covered by $\mathrm{Ag}$ under excessive conditions. As the IPL irradiation time increases, the surface is covered with more Ag, which prevents a UV reaction on the surface.
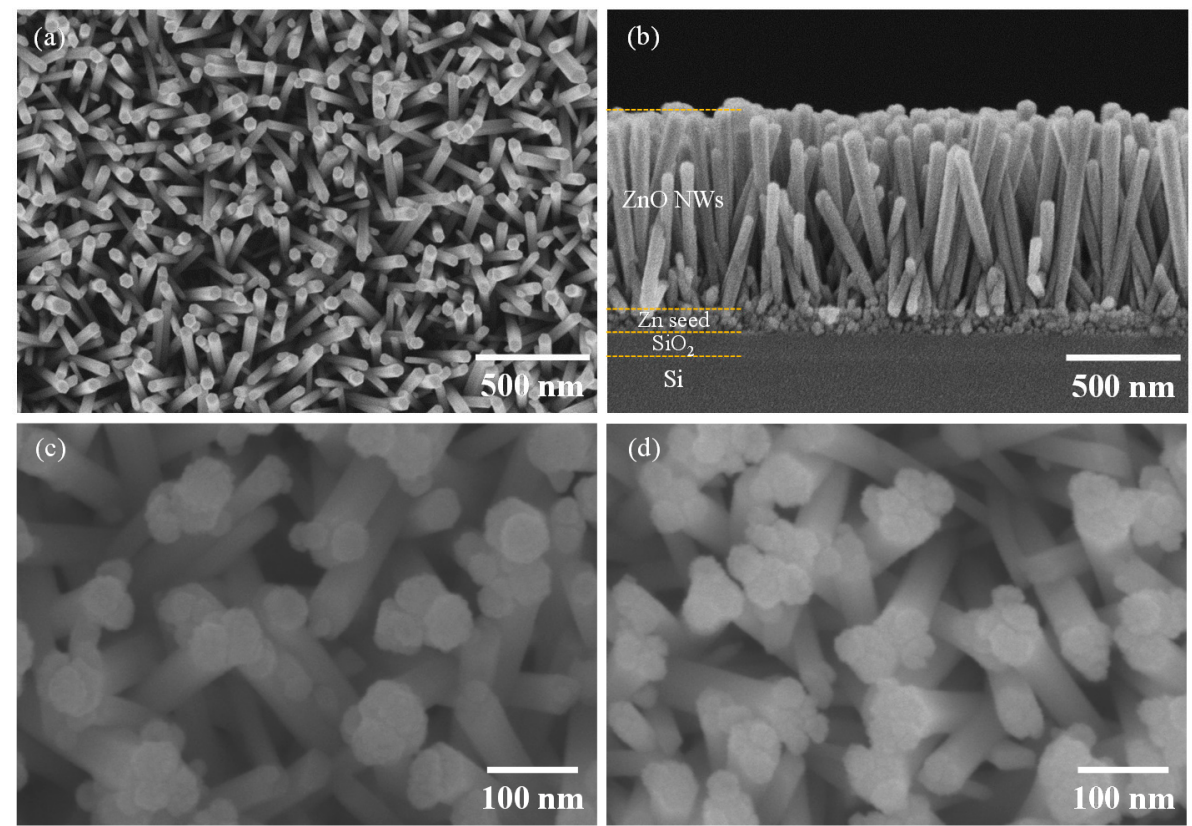

Figure 2. SEM images of (a) top view and (b) cross-sectional view of as-grown $\mathrm{ZnO}$ NWs and $\mathrm{ZnO}$ NWs processed for (c) 5 and (d) $15 \mathrm{~s}$ under excessive conditions. 
Figure 3 displays TEM images and elemental maps of the as-grown and Ag-decorated $\mathrm{ZnO} N W s$. Figure $3 \mathrm{a}-\mathrm{c}$ shows the bright-field TEM images, in which the scale bars represent $50 \mathrm{~nm}$. It is noted in Figure 3b, compared to the as-grown $\mathrm{ZnO} N W$ (Figure 3a), that several circular particles formed on the surface of $\mathrm{ZnO}$ NWs processed in a $\mathrm{AgNO}_{3}$ concentration of $100 \mathrm{nM}$ at IPL irradiation energy of $1 \mathrm{~J} / \mathrm{cm}^{2}$. However, no discernible particle shape was observed on the surface of the $\mathrm{ZnO}$ NWs processed in a $\mathrm{AgNO}_{3}$ concentration of $1 \mathrm{mM}$ at $1 \mathrm{~J} / \mathrm{cm}^{2}$ (Figure 3c). Elemental maps were acquired to confirm the distribution of $\mathrm{Ag}$ elements and demonstrated in Figure $3 \mathrm{~d}-\mathrm{f}$. The $\mathrm{Zn}$ and $\mathrm{O}$ were homogeneously distributed with strong and high-density signals in all three conditions. However, this is not the case for the $\mathrm{Ag}$, which was distributed differently under three conditions. The background signal from the as-grown $\mathrm{ZnO}$ nanowires is shown in Figure 3d, playing a role of control. The Ag was concentrated at the same position with the circular particles in the $\mathrm{ZnO}$ NWs processed in $100 \mathrm{nM}$ at $1 \mathrm{~J} / \mathrm{cm}^{2}$ (Figure 3e). The other part showed a slightly higher signal than the background in as-grown $\mathrm{ZnO}$ NWs. In the $\mathrm{ZnO} \mathrm{NWs}$, processed in $1 \mathrm{mM}$ at $1 \mathrm{~J} / \mathrm{cm}^{2}$, the Ag was evenly distributed on the surface of the $\mathrm{ZnO} \mathrm{NWs}$, as shown in Figure 3f. It is certain that the Ag signal is stronger than the background in the as-grown $\mathrm{ZnO}$ NWs. However, it does not build up large individual nanoparticles enough to be observed in TEM. It can be explained by the following reasons. The strong energy released from IPL induced nucleation from $\mathrm{Ag}^{+}$on the surface of the $\mathrm{ZnO}$ NWs. When the concentration of $\mathrm{AgNO}_{3}$ was high, simultaneous nucleation occurred on all surfaces of the $\mathrm{ZnO}$ NWs. As shown in Figure 3f, circular particles were not yet formed, but Ag was evenly distributed on the surface. However, at the low concentration of $\mathrm{AgNO}_{3}$, nucleation was not uniform on the surface. Ag adsorbed on the surface of the $\mathrm{ZnO} N W$ was aggregated for nucleation and formed into circular particles, as shown in Figure $3 \mathrm{e}$.

Figure 4 illustrates the binding energy among $\mathrm{Ag}, \mathrm{Zn}$, and $\mathrm{O}$ for the bare and $\mathrm{Ag}$ decorated $\mathrm{ZnO}$ NWs. Figure 4a shows the full spectrum of the bare and $\mathrm{ZnO}$ NWs processed in $100 \mathrm{nM}$ at $1 \mathrm{~J} / \mathrm{cm}^{2}$. The spectrum was calibrated based on $C 1 \mathrm{~s}$ at $E_{b}=284.8 \mathrm{eV}$. The peaks from $\mathrm{Zn}$ and $\mathrm{O}$ were the same as the ones reported previously [26]. The peaks at 1021 and $1044 \mathrm{eV}$ in Figure $4 \mathrm{~b}, \mathrm{c}$ are attributed to the $\mathrm{Zn} 2 \mathrm{p}_{3 / 2}$ and $\mathrm{Zn} 2 \mathrm{p}_{1 / 2}$, thus confirming that $\mathrm{Zn}$ exists in a divalent state. There was no change in the peak of $\mathrm{Zn}$ with respect to the concentration of $\mathrm{AgNO}_{3}$ solution and the IPL irradiation energy. It was confirmed that the Ag decoration process did not affect the binding energy of the $\mathrm{Zn}$. The peak at $529.8 \mathrm{eV}$ in Figure $4 \mathrm{~d}$,e was attributed to the $\mathrm{O} 1 \mathrm{~s}$. The spectrum of $\mathrm{O} 1 \mathrm{~s}$ can be fitted to three Gaussian distributions representing different oxygen states. In general, the spectrum of $\mathrm{O} 1 \mathrm{~s}$ can be represented by $\mathrm{O}_{\text {lattice, }} \mathrm{O}_{\text {non-lattice, }}$ and $\mathrm{O}_{\text {adsorption. These }}$ are $\mathrm{O}^{2-}$ ions in the $\mathrm{ZnO}$ crystal lattice, $\mathrm{O}^{2-}$ ions in the oxygen vacancy, and chemisorbed oxygen species on the surface, respectively [38]. Figure $5 \mathrm{a}, \mathrm{b}$ demonstrate the areal ratio of $\mathrm{O} 1 \mathrm{~s}$ with respect to the concentration of $\mathrm{AgNO}_{3}$ solution and IPL irradiation energy, respectively. The areal ratio for $\mathrm{O}_{\text {lattice }}$ was almost constant with no change. The areal ratio of $\mathrm{O}_{\text {adsorption }}$ was maximized at $19.4 \%$ in $\mathrm{ZnO}$ NWs processed in $100 \mathrm{nM}$ at $1 \mathrm{~J} / \mathrm{cm}^{2}$, and $6.9 \%$ and $7.3 \%$ in $\mathrm{ZnO}$ NWs processed in $1 \mathrm{nM}$ and $1 \mathrm{mM}$, respectively (Figure 5a). The ratio of $\mathrm{O}_{\text {non-lattice }}$ was relatively opposite to $\mathrm{O}_{\text {adsorption }}$. The real ratio of $\mathrm{O}_{\text {adsorption }}$ decreased with increasing energy and was measured to be $5.9 \%$ in $100 \mathrm{nM}$ at $5 \mathrm{~J} / \mathrm{cm}^{2}$ (Figure $5 \mathrm{~b}$ ). Furthermore, in the result of energy change, the ratio of $\mathrm{O}_{\text {non-lattice }}$ showed relatively opposite trends. This means that the chemical activity of chemisorbed oxygen species increased, owing to the high conductivity and catalytic properties of Ag NPs [39-42]. In contrast, when the concentration further increased, the surface area exposed to the atmosphere was reduced by Ag, thereby reducing the amount of adsorbed oxygen species. The decrease in $\mathrm{O}_{\text {adsorption }}$ with increasing IPL irradiation energy could also be explained by the same reason. Figure $4 \mathrm{f}, \mathrm{g}$ demonstrates the peaks at 367.3 and $373.3 \mathrm{eV}$ from the $\mathrm{Ag}$ $3 \mathrm{~d}_{3 / 2}$ and $\mathrm{Ag} 3 \mathrm{~d}_{5 / 2}$ with respect to solution concentration and IPL energy, respectively. The scattered dots denote the raw data, while the line represents the fitted data. The difference $(6.0 \mathrm{eV})$ in the binding energy indicates that $\mathrm{Ag}$ has a metallic nature [43]. The binding energy shifted significantly to a lower binding energy compared with the pure metallic $\mathrm{Ag}$ 
(368.2 $\mathrm{eV}$ and $374.2 \mathrm{eV}$ ) [44], which is attributed to the interaction between the Ag NPs and the $\mathrm{ZnO}$ NW. When the Ag NPs and the ZnO NW were attached together, they adjusted the location of the corresponding Fermi energy level to the same value. Thus, there are more free electrons than Ag NPs at the Fermi level. Given that the conduction band (CB) of the $\mathrm{ZnO} N W$ was empty, free electrons can tunnel into the $\mathrm{CB}$, and the valence of the $\mathrm{Ag}$ increases. The binding energy of $\mathrm{Ag}^{+}$was much lower than that of $\mathrm{Ag}^{0}$. Therefore, the binding energy of $\mathrm{Ag} 3 \mathrm{~d}$ shifted to a lower binding energy [45,46]. The peak of $\mathrm{Ag} 3 \mathrm{~d}$ decreased as the concentration and energy decreased, and the peak disappeared at $10 \mathrm{nM}$ or less. The atomic percentage of $\mathrm{Ag}$ was calculated to be $0.174 \mathrm{at} \%$ in $\mathrm{ZnO}$ NWs processed in $1 \mathrm{mM}$ at $1 \mathrm{~J} / \mathrm{cm}^{2}, 0.048$ at $\%$ those processed in $100 \mathrm{nM}$ at $1 \mathrm{~J} / \mathrm{cm}^{2}$, and $0.055 \mathrm{at} \%$ in $100 \mathrm{nM}$ at $5 \mathrm{~J} / \mathrm{cm}^{2}$, respectively. Although Ag NPs were not observed in TEM, the Ag element exists on the surface of the $\mathrm{ZnO}$ NWs, which is confirmed by the elemental map result.
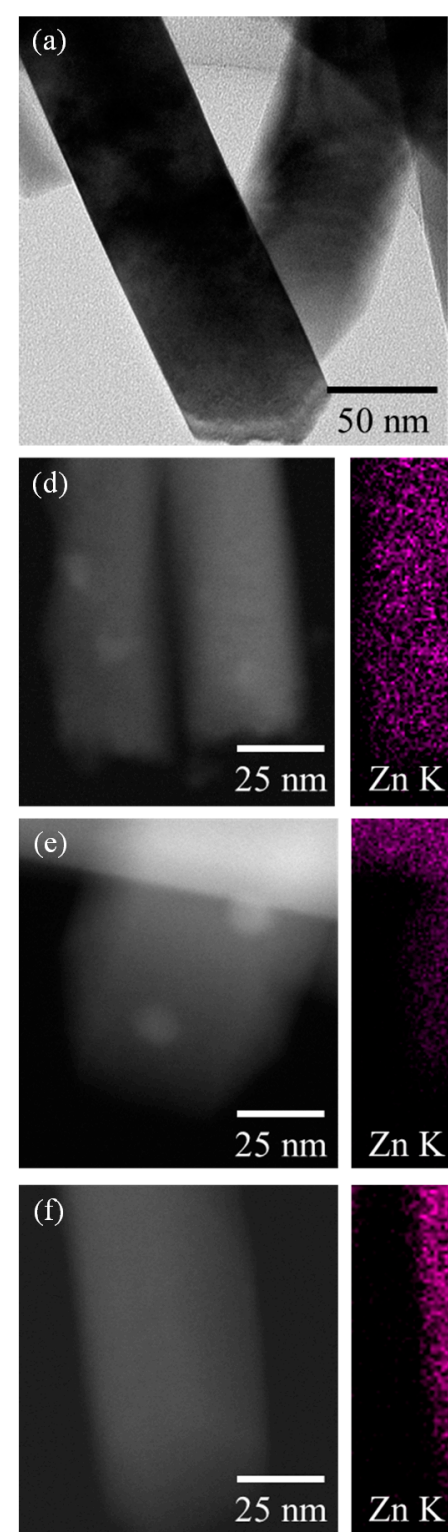
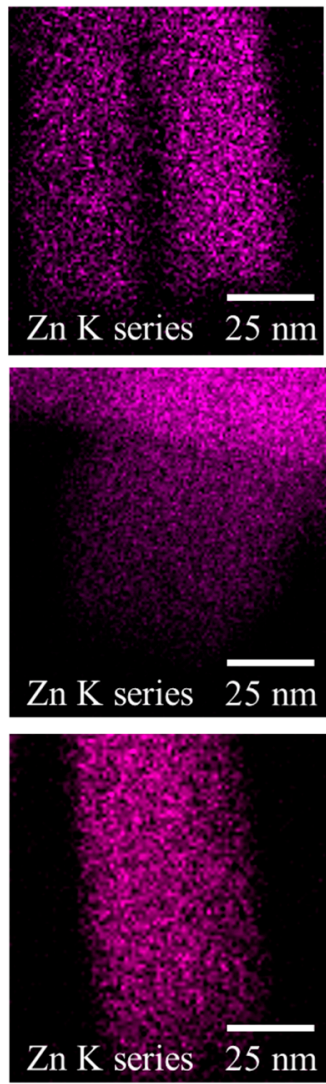
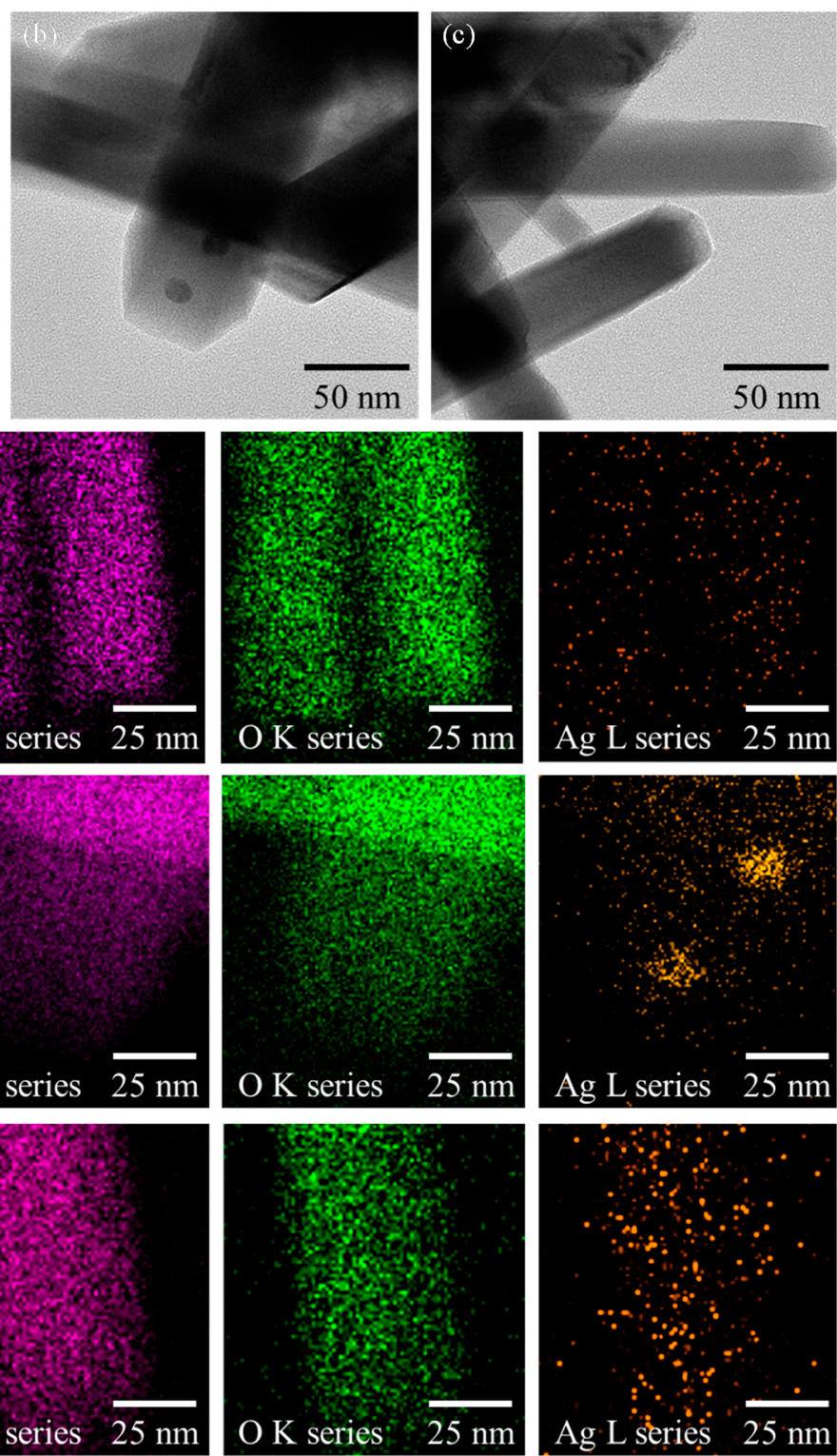
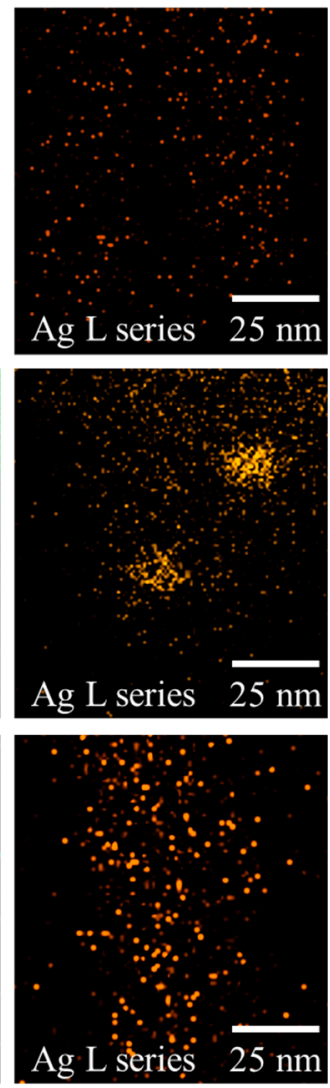

Figure 3. TEM images of (a) the as-grown $\mathrm{ZnO}$ NWs and the Ag-decorated ZnO NWs processed at IPL energy of $1 \mathrm{~J} / \mathrm{cm}^{2}$ and $\mathrm{AgNO}_{3}$ concentration of (b) $100 \mathrm{nM}$, and (c) $1 \mathrm{mM}$. Elemental map image of (d) the as-grown $\mathrm{ZnO} \mathrm{NWs}$ and the Ag-decorated $\mathrm{ZnO} \mathrm{NWs}$ at IPL energy of $1 \mathrm{~J} / \mathrm{cm}^{2}$ and $\mathrm{AgNO}_{3}$ concentration of (e) $100 \mathrm{nM}$, and (f) $1 \mathrm{mM}$. 

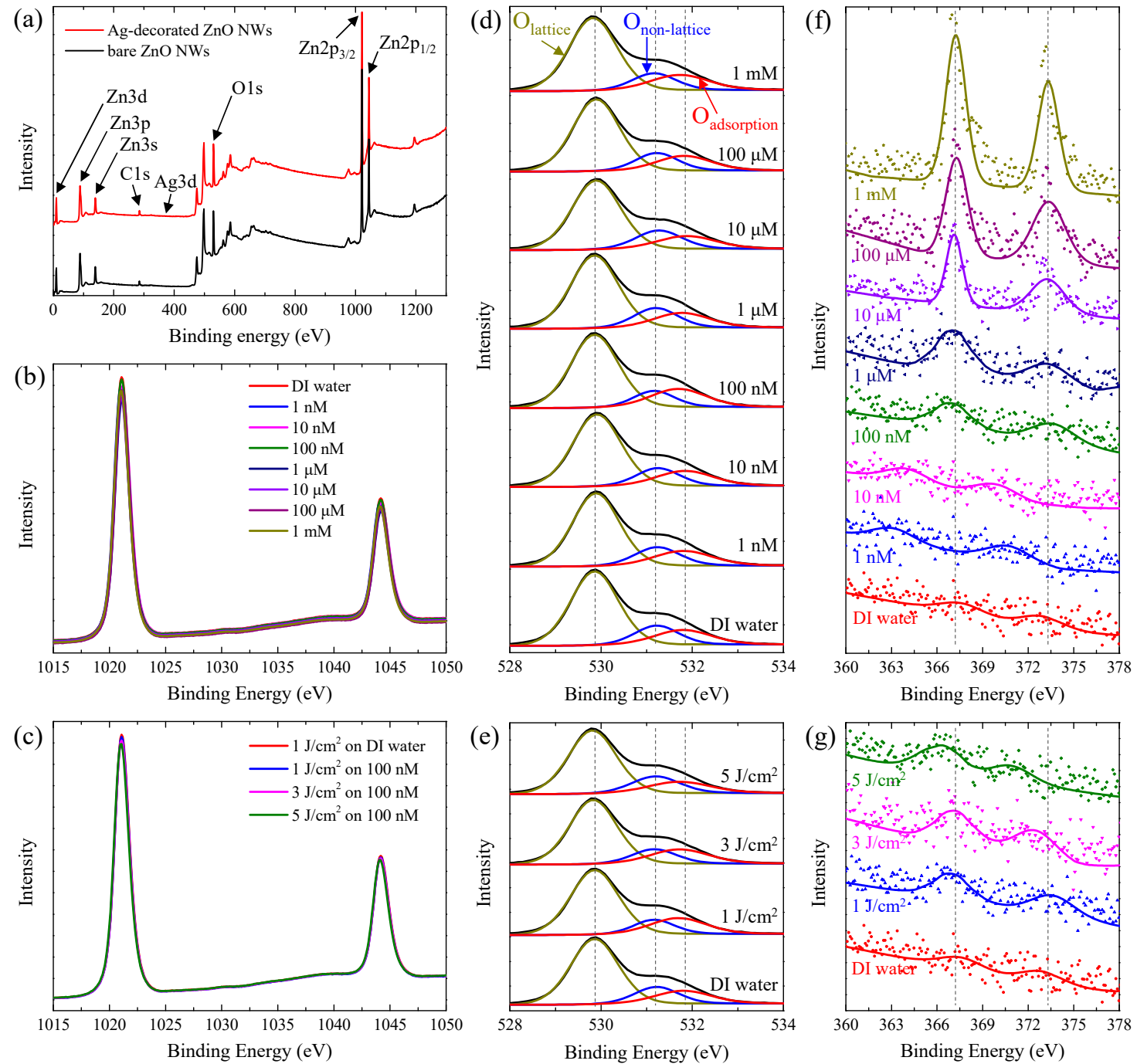

Figure 4. XPS of the bare and Ag-decorated ZnO NWs: (a) survey; (b,c) Zn 2p spectrum; (d,e) O 1s spectrum; and (f,g) Ag $3 \mathrm{~d}$ spectrum. (b,d,f) Plots at different concentrations, $(\mathbf{c}, \mathbf{e}, \mathbf{g})$ plots at different IPL irradiation energies.
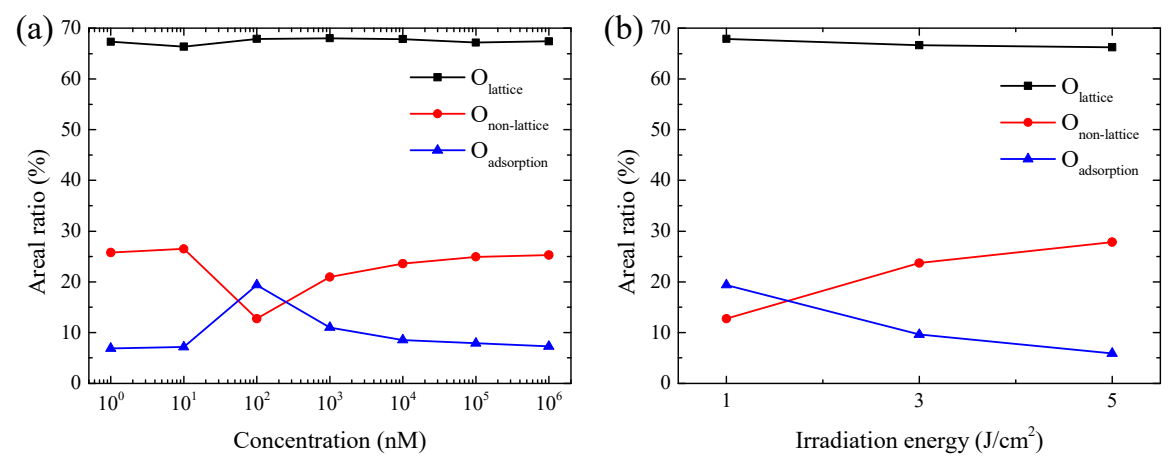

Figure 5. Areal ratio of $\mathrm{O} 1 \mathrm{~s}$ in XPS with respect to (a) $\mathrm{AgNO}_{3}$ concentration and (b) IPL irradiation energy.

The PL spectra from $\mathrm{ZnO}$ NWs are demonstrated in Figure 6. Figure 6a presents the PL spectra of the bare $\mathrm{ZnO}$ NWs processed in $\mathrm{DI}$ water, and the Ag-decorated $\mathrm{ZnO}$ NWs processed in $100 \mathrm{nM}$ at $1 \mathrm{~J} / \mathrm{cm}^{2}$. The PL spectra of the ZnO NWs yielded a sharp peak intensity at $381 \mathrm{~nm}$, mainly owing to the band-band exciton recombination associated with near-band edge emission [47-49]. Figure $6 \mathrm{~b}, \mathrm{c}$ displays the PL spectra with respect to $\mathrm{AgNO}_{3}$ concentration and IPL irradiation energy, respectively. As the concentration of 
$\mathrm{AgNO}_{3}$ solution increases, the intensity of PL increases up to $100 \mathrm{nM}$ and then decreases again. Since the $\mathrm{ZnO}$ NW receives electrons from Ag NPs, the intensity of the PL increases. However, an excessive decoration process lowered the intensity of PL [50]. The PL peak decreased with an increase in the IPL irradiation energy, which is the same reason as in excessive decoration.
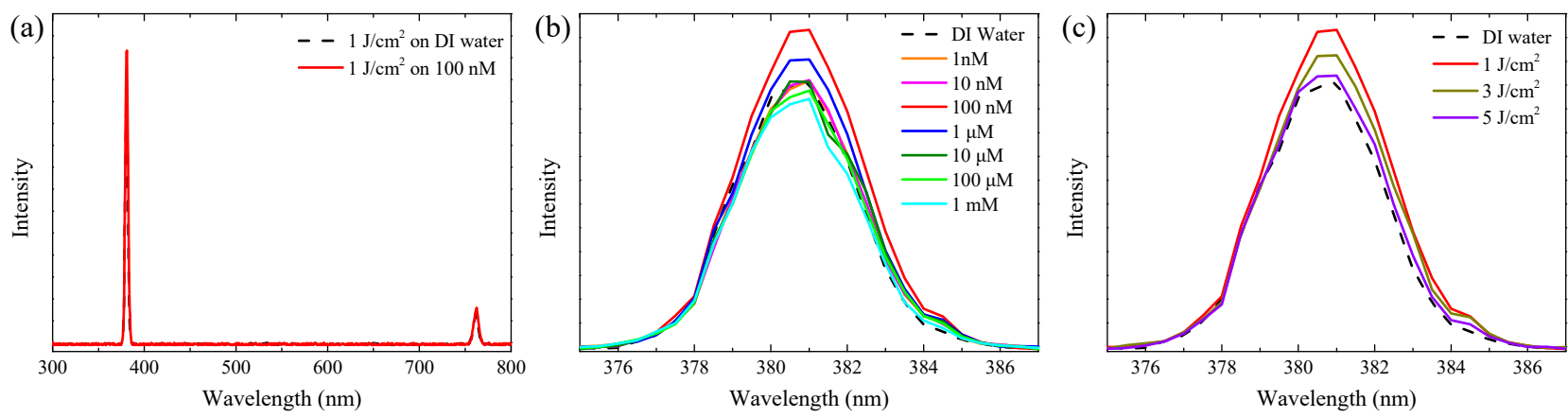

Figure 6. PL spectra of the bare and Ag-decorated $\mathrm{ZnO} N W s:$ (a) full spectra and peak at $381 \mathrm{~nm}$ at different (b) $\mathrm{AgNO}_{3}$ concentrations and (c) IPL irradiation energy.

\subsection{The Performance of Ag-Decorated $\mathrm{ZnO} N W$ UV PDs}

Figure 7 shows the current measurement results at a bias voltage of $1 \mathrm{~V}$. The UV PDs used here employed the bare and Ag-decorated $\mathrm{ZnO}$ NWs processed in DI water and various concentrations of $\mathrm{AgNO}_{3}$ solution. UV PDs were irradiated with a UV LED at a wavelength of $365 \mathrm{~nm}$ and a power density of $850 \mu \mathrm{W} / \mathrm{cm}^{2}$. The temporal response curves were obtained for a time of $50 \mathrm{~s}$. The basic UV detection mechanism of the ZnO NWs is as follows. Electrons in the absence of UV moved to the center of the $\mathrm{ZnO} N W$ owing to the $\mathrm{O}_{2}{ }^{-}$molecules adsorbed on the surface of the $\mathrm{ZnO}$ NW. It forms a thin conduction channel in the center and a thick depletion region on the surface. In the presence of $\mathrm{UV}$, the adsorbed $\mathrm{O}_{2}{ }^{-}$molecules were desorbed, and the $\mathrm{ZnO}$ NW conduction channel expanded, while the depletion region narrowed. The widened conduction channel increased the current flowing between electrodes. If the $\mathrm{O}_{2}{ }^{-}$molecules were not desorbed, the current should be saturated. When the UV was turned off again, $\mathrm{O}_{2}{ }^{-}$molecules were adsorbed on the surface, and the current decreased [7]. According to the experimental results, the highest light current was shown in the $\mathrm{ZnO} N W$ s processed in $100 \mathrm{nM}$ at $1 \mathrm{~J} / \mathrm{cm}^{2}$, as shown in Figure $7 \mathrm{~d}$. Figure 8 shows the responsivity and sensitivity with respect to the concentration of $\mathrm{AgNO}_{3}$ solution and IPL irradiation energy. The responsivity and sensitivity were calculated by the following equations [51,52]:

$$
R=\frac{I_{\text {light }}-I_{\text {dark }}}{P A}
$$

And:

$$
S=\frac{I_{\text {light }}-I_{\text {dark }}}{I_{\text {dark }}} \times 100(\%),
$$

where $R$ is the responsivity, $S$ is the sensitivity, $I_{\text {light }}$ is the light current, $I_{\text {dark }}$ is the dark current, $A$ is the area between two electrodes, and $P$ is the UV power. While the bare $\mathrm{ZnO}$ NWs have a responsivity of $14 \mathrm{~A} / \mathrm{W}$, the most responsivity was $104 \mathrm{~A} / \mathrm{W}$ found in $\mathrm{ZnO}$ NWs processed in $100 \mathrm{nM}$ at $1 \mathrm{~J} / \mathrm{cm}^{2}$, which is 7.43 times increased, as shown in Figure $8 \mathrm{a}$. Meanwhile, the $\mathrm{ZnO}$ NWs processed in $1 \mathrm{mM}$ at $5 \mathrm{~J} / \mathrm{cm}^{2}$ exhibited the lowest responsivity of $5.03 \mathrm{~A} / \mathrm{W}$, which was reduced by $64.1 \%$ compared to the bare $\mathrm{ZnO}$ NWs. The sensitivity was calculated to be the highest of $28,951 \%$ for $\mathrm{ZnO} N W$ s processed in $100 \mathrm{nM}$ at $1 \mathrm{~J} / \mathrm{cm}^{2}$, which is 3.39 times increased, as shown in Figure 8b. In addition, the external quantum 
efficiency (EQE), which is the ability of electrons generated by the excitation of photons, is defined as follows [52].

$$
\mathrm{EQE}=R \times \frac{1240}{\lambda} \times 100 \%,
$$

where $\lambda$ is the wavelength of UV light. It depends on the responsivity $(R)$ at the same wavelength $(\lambda)$. At the largest responsivity, the EQE is calculated to be $35,312 \%$. The increase in responsivity and sensitivity by the Ag decoration process results from the formed Ag NPs. The mechanism of UV detection by Ag NPs is described in Section 3.3. The decrease in responsivity decreased the photocurrent, which is the difference between the light current and dark current, owing to the decrease in oxygen species adsorbed on the surface of the $\mathrm{ZnO} N W s$, like the decrease in the peak of $\mathrm{O}_{\text {adsorption }}$ of XPS. The performance of Ag-decorated $\mathrm{ZnO}$ by IPL was compared with the previous literature and is summarized in Table 1. The performance includes the responsivity, sensitivity, and response/recovery time of PDs based on the $\mathrm{ZnO}$ nanostructures decorated with metal NPs. It is confirmed that our study demonstrated a significant improvement compared to other literature.
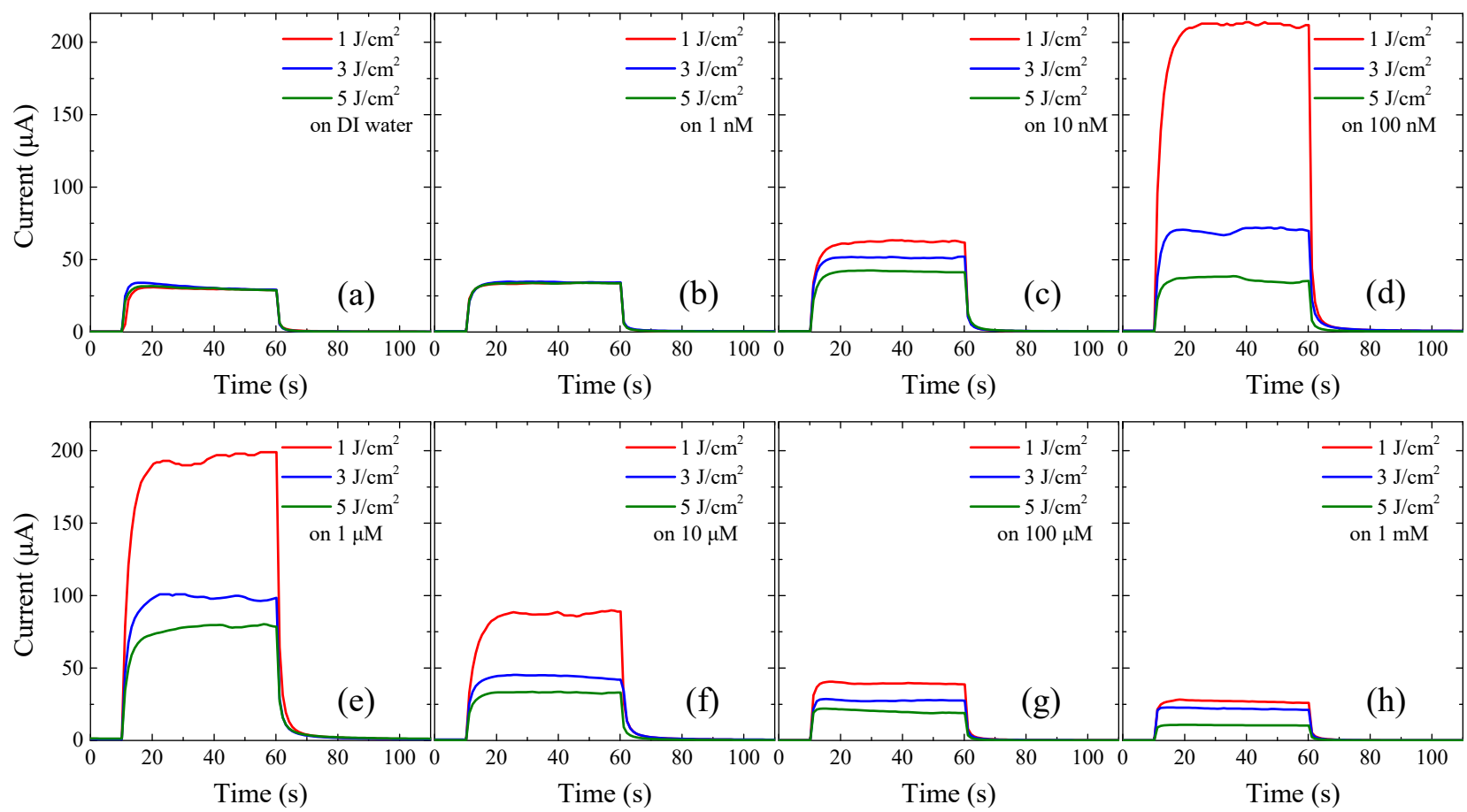

Figure 7. Photocurrent in UV PDs empolying the bare and Ag-decorated $\mathrm{ZnO}$ NWs processed in (a) $\mathrm{DI}$ water and $\mathrm{AgNO}_{3}$ concentration of (b) $1 \mathrm{nM}$, (c) $10 \mathrm{nM},(\mathbf{d}) 100 \mathrm{nM},(\mathbf{e}) 1 \mu \mathrm{M}$, (f) $10 \mu \mathrm{M},(\mathrm{g}) 100 \mu \mathrm{M}$, and (h) $1 \mathrm{mM}$.
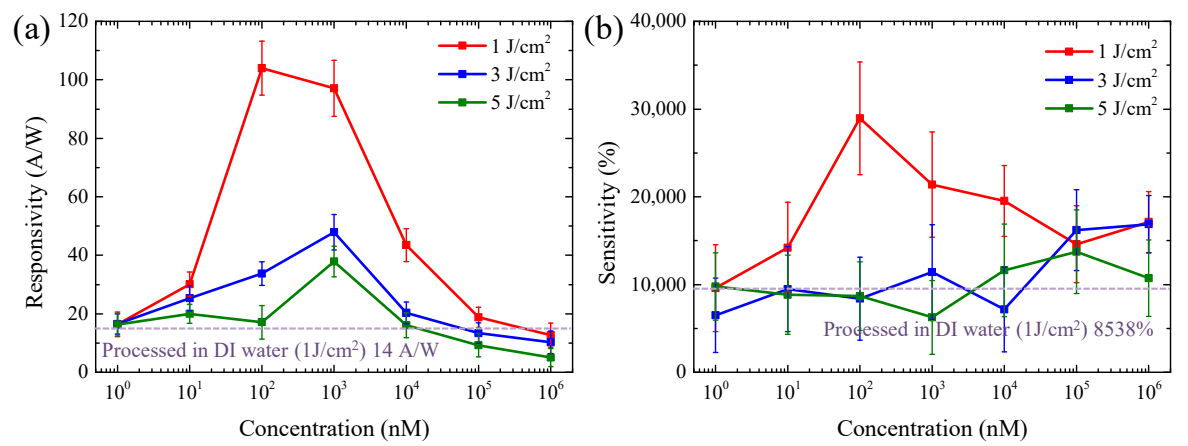

Figure 8. (a) Responsivity and (b) sensitivity with respect to $\mathrm{AgNO}_{3}$ concentration and IPL irradiation energy. 
Table 1. Comparison of performances of $\mathrm{ZnO}$ nanostructure UV PDs decorated with metal NPs.

\begin{tabular}{|c|c|c|c|c|c|c|}
\hline Materials & $\begin{array}{c}\text { Bias Voltage } \\
\text { (V) }\end{array}$ & $\begin{array}{l}\text { Wavelength } \\
\text { (nm) }\end{array}$ & $\begin{array}{l}\text { Responsivity } \\
\text { (A/W) }\end{array}$ & $\begin{array}{c}\text { Sensitivity } \\
(\%)\end{array}$ & $\begin{array}{c}\text { Response/ } \\
\text { Recovery Time } \\
\text { (s) }\end{array}$ & Ref. \\
\hline $\mathrm{ZnO} \mathrm{NWs}$ & 1 & 365 & 14 & 8538 & $4.3 / 3.2$ & This work \\
\hline Ag NPs-ZnO NWs & 1 & 365 & 104 & 28,951 & $5.6 / 2.2$ & This work \\
\hline Ag NPs-ZnO NWs & 5 & 365 & - & $\sim 8970$ & $1.02 / 15.5$ & [53] \\
\hline Ag NPs-ZnO NWs & 0.5 & 365 & - & 239,992 & $4 / 36$ & [33] \\
\hline Ag NPs-ZnO NWs & 5 & 365 & $4.91 \times 10^{6}$ & - & $6.3 / 26.3$ & [54] \\
\hline Ag NPs-ZnO NRs & 0.2 & 380 & 12.4 & - & - & [55] \\
\hline Ag NPs-ZnO NRs & 5 & 400 & $6.52 \times 10^{-3}$ & - & $-/ 157.77$ & [56] \\
\hline Ag NPs-ZnO TFs & 5 & 380 & 2.86 & - & $15 / 330$ & [57] \\
\hline Ag NPs-ZnO TFs & 20 & 365 & $\sim 0.04$ & - & $3.89 / 4.38$ & [58] \\
\hline Au NPs-ZnO NRs & 3 & 365 & - & $\sim 4385$ & - & [59] \\
\hline Au NPs-ZnO NRs & 1 & 365 & 70 & - & - & [60] \\
\hline Au NPs-ZnO NSs & 5 & 325 & $\sim 60$ & - & - & [61] \\
\hline Al NPs-ZnO NRs & 5 & 325 & $\sim 1.65$ & - & $0.03 / 0.035$ & [62] \\
\hline Ni NPs-ZnO NRs & 1 & 325 & 0.124 & - & Prompt rise/rapid fall & [63] \\
\hline
\end{tabular}

Figure 9 shows the various performances of the UV PDs with ZnO NWs processed at optimal conditions. Figure 9 a shows I-V curves on a voltage range of -5 to $5 \mathrm{~V}$ in the absence and presence of UV. It is noted that there was an ohmic contact between the Ag electrode and the Ag-decorated $\mathrm{ZnO}$ NWs. The conductivity of the channel between two electrodes was greatly increased in the presence of UVs. This was ascribed to an expanded conductive channel at the center of $\mathrm{ZnO} N W$ s. The results of the repeated measurements with a 50-s interval are shown in Figure 9b. The response/recovery time and repeatability were excellent. The time to reach $90 \%$ and $10 \%$ of the saturation state is defined as the response and recovery time, respectively. The response/recovery times of the Ag-decorated $\mathrm{ZnO}$ NWs PDs were and 5.6/2.2 s, respectively. The current was measured at increasing powers of UV with 200, 410, 625, and $850 \mu \mathrm{W} / \mathrm{cm}^{2}$, and is shown in Figure 9c. As the UV light power increases, the light current increases, and the response time decreases. The higher power of $\mathrm{UV}$, the more $\mathrm{O}_{2}{ }^{-}$molecules desorbed from the surface of NWs. The decreased response time is attributed to the increased desorption rate of the $\mathrm{O}_{2}{ }^{-}$molecules on the surface.
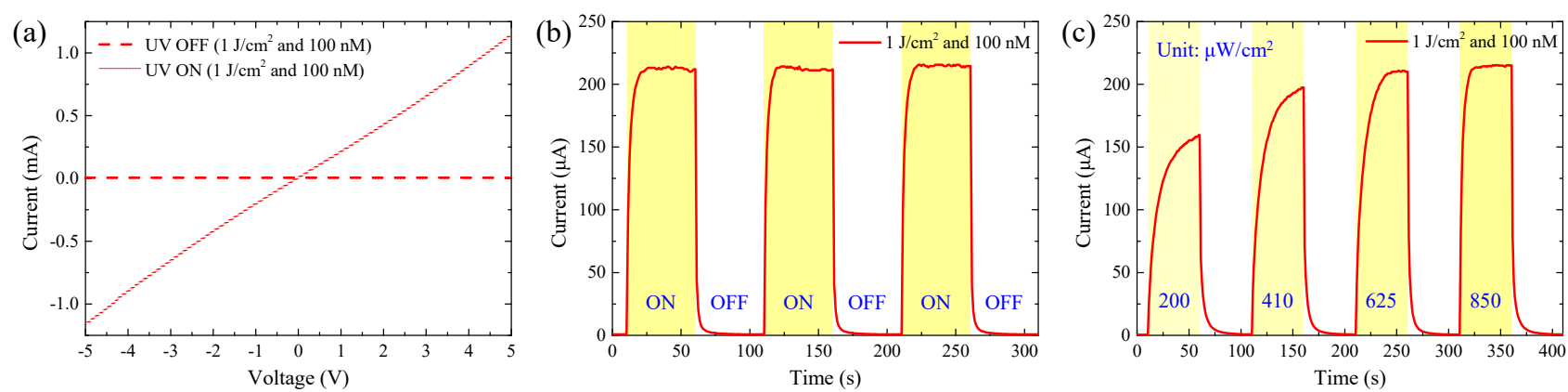

Figure 9. (a) I-V curves in absence and presence of UV, and temporal variations of (b) repeatability, and (c) UV light energy measurements of Ag-decorated the $\mathrm{ZnO}$ NWs.

\subsection{UV-Detection Mechanism}

Herein, a detection mechanism is proposed for Ag-decorated ZnO NW UV PDs, as shown in Figure 10. Ag NPs play a dual role in UV PDs in enhancing the performance of UP PDs. At first, the catalytic properties of Ag NPs increase the chemical activity of the chemisorbed oxygen species, as shown in Figure 4d,e [39-42]. The increase in chemically activated oxygen species widens the depletion region in $\mathrm{ZnO} N W s$, as shown in Figure 10b. More oxygen species are desorbed in the presence of Ag NPs upon exposure to UV light than in the absence of Ag NPs, resulting in more photocurrent in the presence of Ag NPs, as shown in Figure 10c,d. In general, $\mathrm{ZnO}$ NWs synthesized by the hydrothermal method 
are known to have a work function of $5.28 \mathrm{eV}$, an electron affinity of $4.35 \mathrm{eV}$, and a bandgap of $3.37 \mathrm{eV}[64,65]$. The work function of $\mathrm{Ag}$ is $4.26 \mathrm{eV}$; however, the smaller the NP size, the larger the work function [66,67]. The work function is found to be $5.3 \mathrm{eV}$ when the Ag NP size decreases below $30 \mathrm{~nm}$. Consequently, a Schottky barrier was formed at the interface of $\mathrm{Ag} \mathrm{NP}$ and $\mathrm{ZnO} \mathrm{NW}$ owing to the higher work function of Ag NP, as shown in Figure 10e $[33,65,66,68]$. This also leads to the narrowing of the conducting channel of the $\mathrm{ZnO}$ NWs, as shown in Figure 10b. The electrons were generated in the exposure of UV light, and the holes moved toward the Ag NPs owing to the Coulombic force [69]. Some holes were trapped at the interface, and the rest passed through the Schottky barrier and recombined with electrons, as shown in Figure 10f. This results in the narrowing of the depletion region. The photogenerated electrons were secured by the recombination of generated holes with the electrons from Ag NPs, which enhances lifetime. Additionally, Ag NPs enhance the light absorption efficiency by particle-induced light scattering [70]. It increases the number of photogenerated electron-hole pairs.
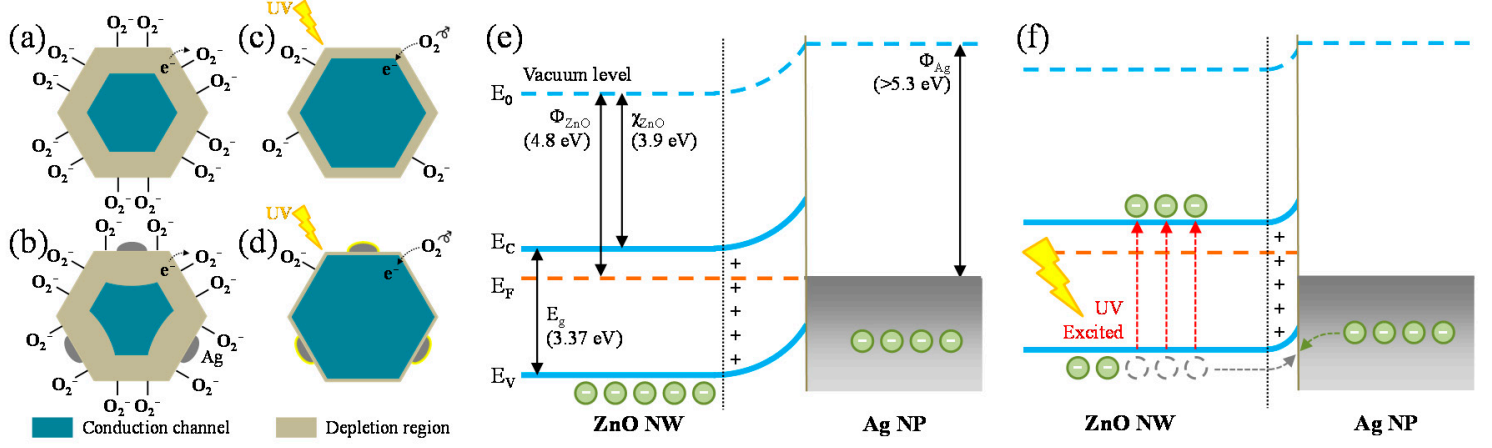

Figure 10. Schematic of the UV detection mechanism of the Ag-decorated ZnO NW PDs: Depletion/conduction channel in $(\mathbf{a}, \mathbf{c})$ bare $\mathrm{ZnO}$ NWs and (b,d) Ag-decorated ZnO NWs in a dark state and upon UV exposure, energy-band diagrams for the $\mathrm{Ag} / \mathrm{ZnO}$ heterojunction (e) in a dark state and (f) upon UV exposure.

\section{Conclusions}

In conclusion, we employed a facile and rapid IPL method to decorate $\mathrm{ZnO}$ NWs with $\mathrm{Ag}$ NPs on the surfaces of the ZnO NWs grown vertically on the substrate. It was confirmed that Ag was successfully decorated on the ZnO NW surface through TEM, elemental maps, and XPS investigation. When the concentration of $\mathrm{AgNO}_{3}$ solution was lower than $100 \mathrm{nM}$, the Ag NPs were not formulated efficiently. The ZnO NWs processed in $100 \mathrm{nM}$ at $1 \mathrm{~J} / \mathrm{cm}^{2}$ exhibited the most superior decoration of Ag NPs along with the highest photocurrent. Further increase in the concentration and exposure energy of IPL resulted in a decrease in electrical performance of the ZnO NW PDs. The decoration process in this study boasts of extremely short ( $\sim 8 \mathrm{~ms}$ ) duration. Our results clearly indicate that the IPL process used in the current work is an efficient way to decorate Ag on $\mathrm{ZnO}$ NWs. Considering that it is difficult to improve the crystal quality of the $\mathrm{ZnO}$ NW grown at low temperatures, this can act as an exemplary guideline for the improvement of UV PD performance.

Author Contributions: Conceptualization, Y.N. and D.L.; methodology, Y.N.; software, H.L. and G.Y.K.; validation, Y.N., J.S., M.K. and D.L.; formal analysis, Y.N.; investigation, Y.N. and J.S.; resources, Y.N.; data curation, H.L. and G.Y.K.; writing - original draft preparation, Y.N.; writingreview and editing, M.K. and D.L.; visualization, Y.N.; supervision, D.L.; project administration, D.L.; funding acquisition, D.L. All authors have read and agreed to the published version of the manuscript.

Funding: This paper was supported by Konkuk University in 2018.

Data Availability Statement: The data presented in this study are available on request from the corresponding author.

Conflicts of Interest: The authors declare no conflict of interest. 


\section{References}

1. Schmidt-Mende, L.; MacManus-Driscoll, J.L. ZnO—nanostructures, defects, and devices. Mater. Today 2007, 10, 40-48. [CrossRef]

2. Kong, Y.C.; Yu, D.P.; Zhang, B.; Fang, W.; Feng, S.Q. Ultraviolet-emitting ZnO nanowires synthesized by a physical vapor deposition approach. Appl. Phys. Lett. 2001, 78, 407-409. [CrossRef]

3. Florica, C.; Preda, N.; Costas, A.; Zgura, I.; Enculescu, I. ZnO nanowires grown directly on zinc foils by thermal oxidation in air: Wetting and water adhesion properties. Mater. Lett. 2016, 170, 156-159. [CrossRef]

4. Greene, L.E.; Law, M.; Goldberger, J.; Kim, F.; Johnson, J.C.; Zhang, Y.; Saykally, R.J.; Yang, P. Low-Temperature Wafer-Scale Production of ZnO Nanowire Arrays. Angew. Chem. Int. Ed. 2003, 42, 3031-3034. [CrossRef] [PubMed]

5. Wang, J.; Gao, L. Hydrothermal synthesis and photoluminescence properties of ZnO nanowires. Solid State Commun. 2004, 132, 269-271. [CrossRef]

6. Rühle, S.; van Vugt, L.K.; Li, H.Y.; Keizer, N.A.; Kuipers, L.; Vanmaekelbergh, D. Nature of Sub-Band Gap Luminescent Eigenmodes in a ZnO Nanowire. Nano Lett. 2008, 8, 119-123. [CrossRef] [PubMed]

7. Park, J.; Lee, J.; Noh, Y.; Shin, K.-H.; Lee, D. Flexible ultraviolet photodetectors with ZnO nanowire networks fabricated by large area controlled roll-to-roll processing. J. Mater. Chem. C 2016, 4, 7948-7958. [CrossRef]

8. Nam, D.; Park, J.; Park, S.; Min, Y.; Noh, Y.; Lee, D. High-density hydrothermal growth of zinc-oxide nanowires using printed resistive heater. Mater. Lett. 2015, 153, 29-32. [CrossRef]

9. Lee, D.; Kim, T.; Park, S.; Lee, S.S.; Ko, S.H. Zinc Oxide Nanowire Forest for Pool Boiling Heat Transfer. Jpn. J. Appl. Phys. 2012, 51, 11PE11. [CrossRef]

10. Song, K.; Noh, J.; Jun, T.; Jung, Y.; Kang, H.-Y.; Moon, J. Fully Flexible Solution-Deposited ZnO Thin-Film Transistors. Adv. Mater 2010, 22, 4308-4312. [CrossRef]

11. Jin, Y.; Wang, J.; Sun, B.; Blakesley, J.C.; Greenham, N.C. Solution-Processed Ultraviolet Photodetectors Based on Colloidal ZnO Nanoparticles. Nano Lett. 2008, 8, 1649-1653. [CrossRef]

12. Mukhopadhyay, S.; Das, P.P.; Maity, S.; Ghosh, P.; Devi, P.S. Solution grown ZnO rods: Synthesis, characterization and defect mediated photocatalytic activity. Appl. Catal. B Environ. 2015, 165, 128-138. [CrossRef]

13. Kakiuchi, K.; Hosono, E.; Kimura, T.; Imai, H.; Fujihara, S. Fabrication of mesoporous ZnO nanosheets from precursor templates grown in aqueous solutions. J. Sol-Gel Sci. Technol. 2006, 39, 63-72. [CrossRef]

14. Xi, Y.; Hu, C.G.; Han, X.Y.; Xiong, Y.F.; Gao, P.X.; Liu, G.B. Hydrothermal synthesis of ZnO nanobelts and gas sensitivity property. Solid State Commun. 2007, 141, 506-509. [CrossRef]

15. Xi, Y.; Song, J.; Xu, S.; Yang, R.; Gao, Z.; Hu, C.; Wang, Z.L. Growth of ZnO nanotube arrays and nanotube based piezoelectric nanogenerators. J. Mater. Chem. 2009, 19, 9260-9264. [CrossRef]

16. Akhtar, N.; Metkar, S.K.; Girigoswami, A.; Girigoswami, K. ZnO nanoflower based sensitive nano-biosensor for amyloid detection. Mater. Sci. Eng. C 2017, 78, 960-968. [CrossRef]

17. Al-Hardan, N.H.; Jalar, A.; Abdul Hamid, M.A.; Keng, L.K.; Ahmed, N.M.; Shamsudin, R. A wide-band UV photodiode based on n-ZnO/p-Si heterojunctions. Sens. Actuator A-Phys. 2014, 207, 61-66. [CrossRef]

18. Tian, C.; Zhang, Q.; Wu, A.; Jiang, M.; Liang, Z.; Jiang, B.; Fu, H. Cost-effective large-scale synthesis of ZnO photocatalyst with excellent performance for dye photodegradation. Chem. Commun. 2012, 48, 2858-2860. [CrossRef] [PubMed]

19. Wang, L.; Kang, Y.; Liu, X.; Zhang, S.; Huang, W.; Wang, S. ZnO nanorod gas sensor for ethanol detection. Sens. Actuator B-Chem. 2012, 162, 237-243. [CrossRef]

20. Hatamie, A.; Khan, A.; Golabi, M.; Turner, A.P.F.; Beni, V.; Mak, W.C.; Sadollahkhani, A.; Alnoor, H.; Zargar, B.; Bano, S.; et al. Zinc Oxide Nanostructure-Modified Textile and Its Application to Biosensing, Photocatalysis, and as Antibacterial Material. Langmuir 2015, 31, 10913-10921. [CrossRef]

21. Lu, M.-P.; Song, J.; Lu, M.-Y.; Chen, M.-T.; Gao, Y.; Chen, L.-J.; Wang, Z.L. Piezoelectric Nanogenerator Using p-Type ZnO Nanowire Arrays. Nano Lett. 2009, 9, 1223-1227. [CrossRef] [PubMed]

22. Djurišić, A.B.; Leung, Y.H. Optical Properties of ZnO Nanostructures. Small 2006, 2, 944-961. [CrossRef] [PubMed]

23. Klingshirn, C. ZnO: From basics towards applications. Phys. Status Solidi B 2007, 244, 3027-3073. [CrossRef]

24. Dhara, S.; Giri, P.K. Enhanced UV photosensitivity from rapid thermal annealed vertically aligned ZnO nanowires. Nanoscale Res. Lett. 2011, 6, 504. [CrossRef]

25. Zhang, J.; Que, W. Preparation and characterization of sol-gel Al-doped ZnO thin films and ZnO nanowire arrays grown on Al-doped ZnO seed layer by hydrothermal method. Sol. Energy Mater. Sol. Cells 2010, 94, 2181-2186. [CrossRef]

26. Jiang, H.; Liu, S.; Liang, L.; Lu, W. Oxygen plasma assisted enhanced photoresponse of ZnO nanowires fabricated by catalyst-free chemical vapor deposition. RSC Adv. 2018, 8, 28928-28933. [CrossRef]

27. Wagata, H.; Ohashi, N.; Katsumata, K.-i.; Segawa, H.; Wada, Y.; Yoshikawa, H.; Ueda, S.; Okada, K.; Matsushita, N. An aqueous solution process and subsequent UV treatment for highly transparent conductive ZnO films. J. Mater. Chem. 2012, 22, 20706-20712. [CrossRef]

28. Zhang, X.; Zhao, J.; Wang, S.; Dai, H.; Sun, X. Shape-dependent localized surface plasmon enhanced photocatalytic effect of ZnO nanorods decorated with Ag. Int. J. Hydrogen Energy 2014, 39, 8238-8245. [CrossRef]

29. Xiang, Q.; Meng, G.; Zhang, Y.; Xu, J.; Xu, P.; Pan, Q.; Yu, W. Ag nanoparticle embedded-ZnO nanorods synthesized via a photochemical method and its gas-sensing properties. Sens. Actuator B-Chem. 2010, 143, 635-640. [CrossRef] 
30. Ko, Y.H.; Yu, J.S. Silver nanoparticle decorated ZnO nanorod arrays on AZO films for light absorption enhancement. Phys. Status Solidi A 2012, 209, 297-301. [CrossRef]

31. Tang, H.; Meng, G.; Huang, Q.; Zhang, Z.; Huang, Z.; Zhu, C. Arrays of Cone-Shaped ZnO Nanorods Decorated with Ag Nanoparticles as 3D Surface-Enhanced Raman Scattering Substrates for Rapid Detection of Trace Polychlorinated Biphenyls. Adv. Funct. Mater. 2012, 22, 218-224. [CrossRef]

32. Slimi, B.; Ben Assaker, I.; Kriaa, A.; Marí, B.; Chtourou, R. One-step electrodeposition of Ag-decorated ZnO nanowires. J. Solid State Electrochem. 2017, 21, 1253-1261. [CrossRef]

33. Tzeng, S.-K.; Hon, M.-H.; Leu, I.-C. Improving the Performance of a Zinc Oxide Nanowire Ultraviolet Photodetector by Adding Silver Nanoparticles. J. Electrochem. Soc. 2012, 159, H440-H443. [CrossRef]

34. Han, Z.; Li, S.; Chu, J.; Chen, Y. Controlled growth of well-aligned ZnO nanowire arrays using the improved hydrothermal method. J. Semicond. 2013, 34, 063002. [CrossRef]

35. Zhang, Z.; Lv, Y.; Yan, J.; Hui, D.; Yun, J.; Zhai, C.; Zhao, W. Uniform ZnO nanowire arrays: Hydrothermal synthesis, formation mechanism and field emission performance. J. Alloys Compd. 2015, 650, 374-380. [CrossRef]

36. Chang, C.W.; Wu, H.T.; Huang, S.H.; Chen, C.K.; Un, I.W.; Yen, T.J. Single-crystalline heterostructure of ZnO nanowire arrays on large Ag microplates and its photocatalytic activity. Acta Mater. 2013, 61, 6993-6999. [CrossRef]

37. Chen, K.J.; Hung, F.Y.; Chang, S.J.; Young, S.J. Optoelectronic characteristics of UV photodetector based on ZnO nanowire thin films. J. Alloys Compd. 2009, 479, 674-677. [CrossRef]

38. Lai, Y.; Xin, P.; Cheng, S.; Yu, J.; Zheng, Q. Plasma enhanced multistate storage capability of single ZnO nanowire based memory. Appl. Phys. Lett. 2015, 106, 031603. [CrossRef]

39. Yan, S.; Li, Z.; Li, H.; Wu, Z.; Wang, J.; Shen, W.; Fu, Y.Q. Ultra-sensitive room-temperature H2S sensor using Ag-In2O3 nanorod composites. J. Mater. Sci. 2018, 53, 16331-16344. [CrossRef]

40. Chen, M.; Wang, H.; Hu, J.; Zhang, Y.; Li, K.; Zhang, D.; Zhou, S.; Zhang, J.; Zhu, Z.; Liu, Q. Near-Room-Temperature Ethanol Gas Sensor Based on Mesoporous Ag/Zn-LaFeO3 Nanocomposite. Adv. Mater. Interfaces 2019, 6, 1801453. [CrossRef]

41. Zhang, X.; Song, D.; Liu, Q.; Chen, R.; Hou, J.; Liu, J.; Zhang, H.; Yu, J.; Liu, P.; Wang, J. Designed synthesis of Ag-functionalized $\mathrm{Ni}$-doped In2O3 nanorods with enhanced formaldehyde gas sensing properties. J. Mater. Chem. C 2019, 7, 7219-7229. [CrossRef]

42. Xu, L.; Xing, R.; Song, J.; Xu, W.; Song, H. ZnO-SnO2 nanotubes surface engineered by Ag nanoparticles: Synthesis, characterization, and highly enhanced HCHO gas sensing properties. J. Mater. Chem. C 2013, 1, 2174-2182. [CrossRef]

43. Li, F.; Wu, S.; Zhang, L.; Li, Z. Ag nanoparticles decorated ZnO nanoarrays with enhanced surface-enhanced Raman scattering and field emission property. J. Mater. Sci. Mater. Electron. 2017, 28, 16233-16238. [CrossRef]

44. Liu, H.; Liu, H.; Yang, J.; Zhai, H.; Liu, X.; Jia, H. Microwave-assisted one-pot synthesis of Ag decorated flower-like ZnO composites photocatalysts for dye degradation and NO removal. Ceram. Int. 2019, 45, 20133-20140. [CrossRef]

45. Chen, C.; Zheng, Y.; Zhan, Y.; Lin, X.; Zheng, Q.; Wei, K. Enhanced Raman scattering and photocatalytic activity of Ag/ZnO heterojunction nanocrystals. Dalton Trans. 2011, 40, 9566-9570. [CrossRef]

46. Zheng, Y.; Zheng, L.; Zhan, Y.; Lin, X.; Zheng, Q.; Wei, K. Ag/ZnO Heterostructure Nanocrystals: Synthesis, Characterization, and Photocatalysis. Lnorg. Chem. 2007, 46, 6980-6986. [CrossRef] [PubMed]

47. Musa, I.; Qamhieh, N.; Mahmoud, S.T. Synthesis and length dependent photoluminescence property of zinc oxide nanorods. Results Phys. 2017, 7, 3552-3556. [CrossRef]

48. Khan, W.; Khan, F.; Ajmal, H.M.; Huda, N.U.; Kim, J.H.; Kim, S.-D. Evolution of Structural and Optical Properties of ZnO Nanorods Grown on Vacuum Annealed Seed Crystallites. Nanomaterials 2018, 8, 68. [CrossRef] [PubMed]

49. Jane, P.; Mariano, G.; Ilaria, R.; Luca De, S.; Ivo, R. Photoluminescence characterization of ZnO nanowires functionalization. In Proceedings of the SPIE Optics + Optoelectronics, Prague, Czech Republic, 13-16 April 2015.

50. Liang, Y.-C.; Lo, Y.-R.; Wang, C.-C.; Xu, N.-C. Shell Layer Thickness-Dependent Photocatalytic Activity of Sputtering Synthesized Hexagonally Structured ZnO-ZnS Composite Nanorods. Materials 2018, 11, 87. [CrossRef]

51. Abdulrahman, A.F.; Ahmed, S.M.; Barzinjy, A.A.; Hamad, S.M.; Ahmed, N.M.; Almessiere, M.A. Fabrication and Characterization of High-Quality UV Photodetectors Based ZnO Nanorods Using Traditional and Modified Chemical Bath Deposition Methods. Nanomaterials 2021, 11, 677. [CrossRef]

52. Li, M.-Y.; Yu, M.; Su, D.; Zhang, J.; Jiang, S.; Wu, J.; Wang, Q.; Liu, S. Ultrahigh Responsivity UV Photodetector Based on Cu Nanostructure/ZnO QD Hybrid Architectures. Small 2019, 15, 1901606. [CrossRef]

53. Liu, Y.; Zhang, X.; Su, J.; Li, H.; Zhang, Q.; Gao, Y. Ag nanoparticles@ZnO nanowire composite arrays: An absorption enhanced UV photodetector. Opt. Express 2014, 22, 30148-30155. [CrossRef] [PubMed]

54. Zhao, X.; Wang, F.; Shi, L.; Wang, Y.; Zhao, H.; Zhao, D. Performance enhancement in ZnO nanowire based double Schottky-barrier photodetector by applying optimized Ag nanoparticles. RSC Adv. 2016, 6, 4634-4639. [CrossRef]

55. Yang, C.; Yu, H.; Su, Y.; Chuang, M.; Hsiao, C.; Kao, T. Noise Properties of Ag Nanoparticle-Decorated ZnO Nanorod UV Photodetectors. IEEE Photonics Technol. Lett. 2016, 28, 379-382. [CrossRef]

56. Dinh, T.M.; Huynh, H.Q.; Mai, T.M.N.; Truong, H.S.; Luong, H.N.; Nguyen, N.P.; Tran, C.K.; Phan, B.T.; Dang, V.Q. Enhancing the performance of photodetectors based on ZnO nanorods decorated with Ag nanoparticles. Semicond. Sci. Technol. 2021, $36,045009$. [CrossRef]

57. Wang, X.; Liu, K.; Chen, X.; Li, B.; Jiang, M.; Zhang, Z.; Zhao, H.; Shen, D. Highly Wavelength-Selective Enhancement of Responsivity in Ag Nanoparticle-Modified ZnO UV Photodetector. ACS Appl. Mater. Interfaces 2017, 9, 5574-5579. [CrossRef] 
58. Wang, H.-C.; Hong, Y.; Chen, Z.; Lao, C.; Lu, Y.; Yang, Z.; Zhu, Y.; Liu, X. ZnO UV Photodetectors Modified by Ag Nanoparticles Using All-Inkjet-Printing. Nanoscale Res. Lett. 2020, 15, 176. [CrossRef]

59. Khan, R.; Uthirakumar, P.; Kim, T.H.; Lee, I.-H. Enhanced photocurrent performance of partially decorated Au nanoparticles on ZnO nanorods based UV photodetector. Mater. Res. Bull. 2019, 115, 176-181. [CrossRef]

60. Zhang, H.; Zhao, Y.; Geng, X.; Huang, Y.; Li, Y.; Liu, H.; Liu, Y.; Li, Y.; Wang, X.; Tian, H.; et al. Au Nanoparticles-Decorated Surface Plasmon Enhanced ZnO Nanorods Ultraviolet Photodetector on Flexible Transparent Mica Substrate. IEEE J. Electron Devices Soc. 2019, 7, 196-202. [CrossRef]

61. Gogurla, N.; Sinha, A.K.; Santra, S.; Manna, S.; Ray, S.K. Multifunctional Au-ZnO Plasmonic Nanostructures for Enhanced UV Photodetector and Room Temperature NO Sensing Devices. Sci. Rep. 2014, 4, 6483. [CrossRef]

62. Lu, J.; Xu, C.; Dai, J.; Li, J.; Wang, Y.; Lin, Y.; Li, P. Improved UV photoresponse of ZnO nanorod arrays by resonant coupling with surface plasmons of Al nanoparticles. Nanoscale 2015, 7, 3396-3403. [CrossRef] [PubMed]

63. Jayalakshmi, G.; Saravanan, K. High-performance UV surface photodetector based on plasmonic Ni nanoparticles-decorated hexagonal-faceted $\mathrm{ZnO}$ nanorod arrays architecture. J. Mater. Sci. Mater. Electron. 2020, 31, 5710-5720. [CrossRef]

64. Subha, P.P.; Jayaraj, M.K. Enhanced room temperature gas sensing properties of low temperature solution processed $\mathrm{ZnO} / \mathrm{CuO}$ heterojunction. BMC Chem. 2019, 13, 4. [CrossRef]

65. Li, X.; Chen, Y.; Kumar, A.; Mahmoud, A.; Nychka, J.A.; Chung, H.-J. Sponge-Templated Macroporous Graphene Network for Piezoelectric ZnO Nanogenerator. ACS Appl. Mater. Interfaces 2015, 7, 20753-20760. [CrossRef] [PubMed]

66. Schnippering, M.; Carrara, M.; Foelske, A.; Kötz, R.; Fermín, D.J. Electronic properties of Ag nanoparticle arrays. A Kelvin probe and high resolution XPS study. PCCP 2007, 9, 725-730. [CrossRef]

67. Kumatani, A.; Li, Y.; Darmawan, P.; Minari, T.; Tsukagoshi, K. On Practical Charge Injection at the Metal/Organic Semiconductor Interface. Sci. Rep. 2013, 3, 1026. [CrossRef]

68. Yang, F.; Zheng, M.; Zhao, L.; Guo, J.; Zhang, B.; Gu, G.; Cheng, G.; Du, Z. The high-speed ultraviolet photodetector of ZnO nanowire Schottky barrier based on the triboelectric-nanogenerator-powered surface-ionic-gate. Nano Energy 2019, 60, 680-688. [CrossRef]

69. Liu, K.; Sakurai, M.; Liao, M.; Aono, M. Giant Improvement of the Performance of ZnO Nanowire Photodetectors by Au Nanoparticles. J. Phys. Chem. C 2010, 114, 19835-19839. [CrossRef]

70. Atwater, H.A.; Polman, A. Plasmonics for improved photovoltaic devices. Nat. Mater. 2010, 9, 205-213. [CrossRef] 